\title{
Gestión medio ambiental y participación: una experiencia costarricense de política social construida desde las comunidades
}

\author{
Marcos Chinchilla Montes*
}

\author{
A Yamisela... \\ quien desde sus acciones \\ y luchas diarias \\ me puso frente a esta experiencia.
}

\section{RESUMEN}

Este documento analiza una de las experiencias de participación social derivadas del proyecto de investigación "Participación ciudadana y construcción de ciudadanía en la Península de Osa, Puntarenas"1.

Palabras clave: Organización comunitaria / Participación / Burocratización / Repolitización.

\section{ABSTRACT}

This document analyzes one of the experiences of social participation derived from the research project "Citizen Participation and construction of citizenship in the Peninsula of Oso, Puntarenas". This investigation was carried out in association with Marta Picado Mesén, social worker. Costa Rica.

Key words: Communitarian organization / Participation / Bureaucratization / Politicization.

* Costarricense. Trabajador Social. Académico de la Escuela de Trabajo Social de la Universidad de Costa Rica. Representante centroamericano ante la Asociación Latinoamericana de Enseñanza e Investigación en Trabajo Social. E-mail: mchinchi@fcs.ucr.ac.cr

I Este proyecto de investigación fue realizado en conjunto con Marta Picado Mesén, trabajadora social. Costa rica. 


\section{Introducción: El medio ambiente y los Derechos Humanos}

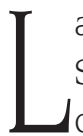

as Ciencias Sociales latinoamericanas, entre ellas el Trabajo Social, han prestado poca atención al desarrollo conceptual del tema medio ambiental. No es sino hasta la década de los 60-70 que, en el marco de los movimientos sociales que caracterizaron esta época, se introduce esta preocupación en diferentes organismos internacionales, particularmente en las Naciones Unidas.

Esta preocupación se justificó por el creciente impacto que el desarrollo industrial y el crecimiento demográfico tenía sobre los ecosistemas. La humanidad no sólo se enfrentaba a la incertidumbre de una guerra nuclear entre las superpotencias de la época, sino a una creciente hambruna en los países más pobres del planeta. En ese contexto, las superpotencias no podían arriesgar sus esfuerzos de desarrollo económico e industrial, menos exponerse a quedarse atrás la una de la otra; más allá de cuál sistema podía ser mejor -capitalismo o socialismo- y cuál producía más bienes de consumo para su población, el medio ambiente recibía un impacto negativo. La degradación ambiental era una amenaza más tangible para la humanidad que el mismo holocausto atómico o una hambruna generalizada.

Era necesario repensar la forma cómo el ser humano se relacionaba con el ambiente, cómo lo aprovechaba y cómo lo protegía². En ese contexto, y luego de un estudio encargado por la Comisión Mundial sobre el Medio Ambiente y Desarrollo de las Naciones Unidas, surge el informe "Nuestro Futuro Común" (conocido también como Informe Brundtland, 1987) el cual plantea el concepto sostenibilidad, asociado con el de desarrollo sostenible. El mismo se concibe como el "desarrollo que satisface las necesidades del presente, sin comprometer la capacidad para que las futuras generaciones puedan satisfacer sus propias necesidades".

\footnotetext{
Valga la pena mencionar que esta forma de repensar la relación con el medio ambiente no es novedosa, a lo largo y ancho de América Latina, muchas comunidades indígenas tenían y tienen una relación de simbiosis con el medio ambiente, se sienten parte integral de éste. Incluso en 1856 el Cacique Seattle había advertido al gobierno de los Estados Unidos de América, el riesgo que corría su pueblo por la forma cómo se trataba al medio ambiente.
} 
Este concepto ha sido la piedra angular de buena parte del discurso ambientalista de la actualidad, sea que lo asuman los gobiernos, los organismos internacionales o los diferentes sectores de la sociedad civil. Las contradicciones afloran por doquier, particularmente porque, para mantener el actual nivel de desarrollo capitalista y el consumo que se le asocia, es necesario utilizar a ultranza los recursos que brinda el ambiente.

Un avance importante en materia ambiental tiene que ver con el hecho de asociar el desarrollo sostenible y la protección del medio ambiente con la categoría derechos humanos. Esto se vino haciendo de forma progresiva desde los años ' $60^{3}$, y en ese esfuerzo se enmarca el Informe Brundtland y la Declaración de Río de Janeiro del año 1992. Para ese mismo año, el Instituto Interamericano de Derechos Humanos organizó en Brasil (tres meses antes de la Declaración de Río de Janeiro) un seminario que desembocó en la publicación del libro Derechos Humanos, Desarrollo Sustentable y Medio Ambiente, en el cual se establece con precisión la integración que existe entre estas tres categorías, se reconoce igualmente la necesidad y urgencia de la participación social para avanzar en pro de la sostenibilidad ambiental y protección del medio ambiente.

Con esta renovada comprensión, los Derechos Humanos ya no se limitarán a la protección y tutela de los derechos civiles (personales y políticos) y económicos y culturales, sino que cubrirán el derecho a un medio ambiente digno y sano que permita la reproducción, desarrollo, disfrute y convivencia de la humanidad.

\section{Participación social en el contexto costarricense}

La participación social ha sido una expresión colectiva ambivalente en el caso costarricense. Durante la década de los años '20 y '30 del siglo XX, existían diferentes manifestaciones de participación y organización comunitaria que eran desafiantes del poder hegemónico

En la presentación de la sección Ecología, Medio Ambiente y Trabajo Social, Juan Barreix expresa que el Movimiento de la Reconceptualización del Trabajo Social puso otros "procesos en marcha" dentro del Trabajo Social, entre ellos el medio ambiental. Ello respondía a una sensibilidad que ya existía por el tema a mediados de la década de 1960. Para mayor información véase el sitio www.ts.ucr.ac.cr/ reconceptualizacion.htm 
del aquel entonces, a esta se sumaban las experiencias desarrolladas por el partido comunista, particularmente con los sindicatos bananeros en la zona atlántica del país, lo que llevó a la conformación de un vigoroso movimiento social articulado con estos sindicatos. La década de los '40 experimentó importantes manifestaciones de participación social, articuladas al proceso de defensa de las garantías sociales -vehiculizadas por la alianza que se estableció entre el gobierno del Dr. Rafael Ángel Calderón, el Partido Comunista y la Iglesia Católica- y al surgimiento de una nueva burguesía industrial, las que llegaron a su punto culminante con la guerra civil del año '48 que enfrentó a estas dos fuerzas (Salazar, 1985)

Luego de este conflicto político, se amplió y fortaleció la institucionalidad costarricense y se generaron mecanismos políticos de representación e inclusión de los intereses sociales, lo que llevó a una reducción de los espacios de participación social dado que la matriz política estaba en capacidad de dar respuesta a muchos de estos conflictos e intereses.

En el año 1973, en el marco de la aprobación de un proyecto de ley para concesionar la explotación de aluminio en la zona sur de país, se presentaron importantes muestras de participación social y descontento popular en torno al proyecto. Aunque el mismo fue aprobado por la Asamblea Legislativa ${ }^{4}$, en el imaginario social costarricense se mantiene la convicción de la importancia de esta lucha y la relevancia que tuvo como acción anti imperialista y en pro de la defensa de los recursos naturales. No sería sino hasta el año 2000 cuando la situación política del país reuniría las condiciones necesarias para que se gestaran importantes acciones de participación social que permitieron evitar la privatización del sistema nacional de telecomunicaciones y electricidad, y se desarrolló un escenario político que facilitó la reconfiguración del panorama partidario que dominaba desde los años 80 .

No es que durante este espacio de 30 años no existiera participación social, pero la misma era sumamente limitada y escasamente capaz

La Lucha contra ALCOA -Aluminiun Company of América- si bien no fue ganada ni en el campo legislativo ni en las calles, sí fortaleció la organización popular de aquel entonces, permitió la articulación de numerosos sectores sociales y generó una suerte de sentimiento de unidad por la defensa de la institucionalidad costarricense. Dicho sea de paso, la compañía norteamericana nunca desarrolló la explotación del aluminio, 
de enfrentar el embate neoliberal. El primer lustro del nuevo siglo tiene un panorama diferente en materia de participación social, esta se ha ampliado, algunos actores desaparecieron, otros se fortalecieron o redefinieron, y el escenario participativo ha visto surgir nuevos actores, y, particularmente, un esfuerzo sostenido por articular intereses y acciones en pro de un proyecto societal más inclusivo en que el Estado siga teniendo un rol fundamental en la distribución de la riqueza.

\section{Participación social en el marco del medio ambiente: el caso costarricense}

En esta sección desarrollaremos una breve síntesis del proceso de participación social en el marco del medio ambiente que se ha dado en las últimas décadas en Costa Rica, el surgimiento de la ASOCOVIRENAS en el marco de un esfuerzo por burocratizar la participación, las manifestaciones de su singularidad, el porqué de su esfuerzo político, y un punteo de acciones en las que esta organización identifica retos.

Un aspecto de gran relevancia en materia ambiental está relacionado con el artículo 50 de la Constitución Política de Costa Rica, el cual plantea:

"El Estado procurará el mayor bienestar a todos los habitantes del país, organizando y estimulando la producción y el más adecuado reparto de la riqueza. Toda persona tiene derecho a un ambiente sano y ecológicamente equilibrado. Por ello, está legitimada para denunciar los actos que infrinjan ese derecho y para reclamar la reparación del daño causado. El Estado garantizará, defenderá y preservará ese derecho. La ley determinará las responsabilidades y las sanciones correspondientes". (Reformado por Ley No. 7412 del 3 de junio de 1994)

Este artículo no sólo reconoce el derecho de la población nacional a disfrutar de un medio ambiente digno, ecológicamente equilibrado y sostenible, sino su derecho a participar en iniciativas orientadas a detener la degradación ambiental y asegurar su sostenibilidad.

A criterio de Fallas (1992), los primeros esfuerzos nacionales por conservar el medio ambiente lo dieron los grupos precolombinos, la mayoría de estos articulados a una experiencia de vida en la que 
las personas y el medio ambiente se reconocían como similares y complementarios, parte de un mismo equilibrio y universo.

Hacia finales del siglo XIX el naturalismo -como corriente científica- se hace presente en el país por medio de diferentes investigadores extranjeros. Si bien su preocupación fundamental era el conocimiento antes que la protección de los recursos, sienta las primeras condiciones para que científicos nacionales incursionen en este campo.

En 1926 se establece la Escuela Nacional de Agricultura, la cual es considerada como el primer antecedente para forjar acciones orientadas a la conservación ${ }^{5}$, aunque su esfuerzo sucumbió ante el proyecto desarrollista.

La centralización estatal característica del Estado Desarrollista también se expresó en el campo ambiental. La mayoría de los esfuerzos de protección ambiental se convirtieron en legislación y acciones concretas de las instituciones públicas, enmarcadas claro está, en no contradecir las necesidades del modelo productivo. Como ya era tradición, la naturaleza suplía insumos básicos para desarrollar el proceso productivo y de acumulación capitalista.

En la década de 1960 se profundizan las condiciones que darían pie a las acciones reivindicativas en materia de protección del ambiente, entre estas destacan: la incorporación de una cátedra específica en la Universidad de Costa Rica sobre el tema ambiental, una legislación que reconoce que todas las especies silvestres son propiedad de la nación, y la creación de instituciones y centros de investigación referidos a la materia.

Para inicios de los '70 la crisis ambiental era evidente a nivel planetario; fuera en las sociedades capitalistas o socialistas, la carrera por el crecimiento económico y el progreso comprometía la sostenibilidad ambiental. En ese contexto surgen esfuerzos internaciona-

\footnotetext{
Este autor destaca la aprobación de legislación ambiental muy diversa, previa a 1925 , pero expresa que la misma se explica por la presión de los sectores agroexportadores y burgueses en función de sus intereses económicos, en diferentes consultas no fue posible identificar alguna referencia a presiones populares en esa materia; sería oportuno conocer si ésta sólo se explica en función de la presión social ejercida por los sectores dominantes, o también Intervinieron comunidades y otros grupos sociales organizados de la época. Este sería un valioso tema de investigación desde la Ciencia Política y la Historia.
} 
les por analizar los alcances de la crisis ambiental -Club de Roma, 1968- y grupos ambientalitas de alcance mundial como Greenpeace y Amigos de la Tierra.

Luego de un período de relativa calma social en que la presencia de movilizaciones sociales vinculadas con la cuestión social era prácticamente nula, en los años '70 ese equilibrio muestra fisuras y reaparecen diversas manifestaciones de movimientos sociales, en este caso, incluyendo el tema ambiental en su agenda de lucha. Este período de efervescencia social coincide con manifestaciones sociales a nivel mundial como la guerra contra Vietnan, la Primavera de Praga, la preocupación por una guerra nuclear, la revolución cubana, la ampliación de los movimientos estudiantiles en Europa y América, etc. Sin lugar a dudas, es una de las claras manifestaciones de que el boon económico de los 50-60 se había acabado y que el capitalismo entraba en una nueva época de crisis que se correspondía con el ascenso de los movimientos sociales en todo el orbe ${ }^{6}$.

La conformación de un movimiento ambiental que integre tanto la dimensión política reivindicativa como una permanencia temporal sostenida -condiciones propias de los movimientos sociales (Camacho, 1987)- se da justamente en los años '70 con la aparición de la Asociación Costarricense para la Conservación de la Naturaleza (ASCONA), aunque esto no desconoce un conjunto de esfuerzos individuales y colectivos que antecedieron la constitución del movimiento ambiental costarricense ${ }^{7}$.

Según Fallas (1992), en el caso de Costa Rica el conservacionismo se manifestaba en unas cuantas organizaciones ambientales y un grupo de intelectuales vinculados a las universidades e instituciones públicas. Aunque estos tenían una limitada capacidad de incidencia

6n ese sentido coincidimos con Garretón (2002) cuando afirma que los movimientos sociales responden a una lógica de expansión-depresión económica. Para este autor, cuando la situación económica tiende a ser favorable, sostenida y con crecimiento económico, tienden a menguar los movimientos sociales y sus reivindicaciones. Pero cuando se entra en un periodo de recesión económica, los movimientos sociales se rearticulan por periodos tan extensos como la duración de la misma crisis económica.

7 Un esfuerzo de reconstrucción de los orígenes políticos del movimiento ambiental costarricense puede consultarse en Chacón, García y Guier, 1993. En este se hace mención a un conjunto de costarricenses y extranjeros que dieron los primeros pasos en materia de conservación del ambiente, para posteriormente pasar a constituir la organización no gubernamental ASCONA. 
en la formulación de políticas públicas, era evidente que la preocupación por los temas ambientales tomaba mayor fuerza y se asociaba con otras problemáticas sociales. En ese marco, por ejemplo la lucha contra la Aluminiun Company of America (ALCOA) no sólo buscaba proteger la soberanía nacional, sino que también incluía un componente de "oposición a la entrega de los recursos naturales del país" (Fallas, 1992: 81).

A criterio de este autor, la lucha contra ALCOA "acelera la aparición de las primeras organizaciones ambientalistas"8 y con el paso del tiempo se fueron sumando nuevas luchas en pro del ambiente? Estas acciones se han caracterizado en primera instancia por su cobertura nacional, y posteriormente por atender necesidades con un carácter más local o regional, sin dejar de atender problemas ambientales de trascendencia nacional.

Casi veinte años después de la lucha contra $\operatorname{ALCOA}^{10}$, las comunidades del sur de Costa Rica, particularmente las establecidas en la zona costera de la Península de Osa, desarrollaron una importante gesta política contra la compañía canadiense Ston Forestal, la cual pretendía sembrar cientos de hectáreas con madera, crear una fábrica procesadora de astillas de madera e instalar un muelle de embarque en Punta Estrella. Todas estas actividades industriales afectarían el delicado equilibrio ecológico de la zona, uno de los más ricos de toda América Latina. La movilización de actores locales, comunidades y Organizaciones no Gubernamentales (ONGs) finalmente influyeron para que el gobierno (Administración Figueres Olsen, 1994-1998) interviniera y detuviera los planes de la mencionada compañía.

8 Destaca la creación del Comité de Defensa el Patrimonio Nacional, la Asociación Costarricense para la Conservación de la Naturaleza, el Comité Nacional pro Conservación de la Naturaleza y una serie de grupos comunales que fueron asumiendo luchas puntuales asociadas con problemas de sus comunidades o regiones.

9 Menciona la defensa de la Reserva Biológica de la Isla del Caño, las acciones contra la instalación de un oleoducto que cruzaría del pacífico al atlántico, las acciones de protección sobre el Parque Nacional Braulio Carrillo, la defensa de la tortuga verde y un largo listado de actividades orientadas a la protección de los recursos naturales y la calidad de vida.

10 Esto no quiere decir que en ese periodo intermedio no se presentaran acciones sociales en pro del ambiente, sino que no tuvieron la magnitud de la lucha contra ALCOA o la Ston Forestal. 
El desarrollo del movimiento conservacionista demuestra que a lo largo de los últimos 35 años ha aumentado no sólo la cantidad de organizaciones, sino la democratización en su composición: nacionales, regionales, locales; conformadas por intelectuales o por personas que simplemente están preocupadas por la conservación del ambiente; afines e instrumentales al gobierno, intermediarias pero contestatarias al gobierno, plenamente autónomas pero buscando influir no sólo en la definición de políticas públicas sino también en la organización comunitaria.

El movimiento conservacionista es una clara manifestación de espacios de construcción de ciudadanía que tienen una cobertura global, regional, nacional y local; en el que participa el Estado, organizaciones internacionales, ONGs, empresarios, comunidades, grupos indígenas y otra clase de actores sociales; y entre los que no siempre hay una plena coincidencia entre el modo en que deben aprovecharse los recursos medio ambientales, la forma como deben participar los diferentes interesados y el tipo de decisiones a los cuales pueden acceder.

Estas expresiones de participación por lo general" ${ }^{11}$ están enmarcadas en una legislación medioambiental que define qué se protege, quién lo protege y qué características asume la participación social.

\section{COVIRENAS: burocratización de la participación}

En el campo ambiental, y particularmente para el caso que analiza este artículo, es necesario destacar que durante la administración Calderón Fournier (1990-1994) se aprobó la Ley de Conservación de la Vida Silvestre (ley 7317, 30 de octubre 1992), en términos generales, esta ley tipifica tipos de recursos ambientales, establece

"Deseamos insistir que no todas las expresiones de participación social están enmarcadas y condicionadas jurídicamente. Palma (2002) plantea que la ciudadanía deviene de un proceso histórico en que las personas se constituyen en sujetos sociales, esto es, que toman conciencia de su potencialidad y derecho a participar en la toma de decisiones. En años recientes esos espacios de participación no se limitan solo a la interacción entre Estado y sociedad civil, a criterio del autor, una numerosa cantidad de personas se desvinculan de los espacios tradicionales de participación -institucionalizados- y buscan formas novedosas de asociarse en sus comunidades, y con propósitos políticos que no siempre se dirigen a buscar transformaciones estructurales en la sociedad. 
delimitaciones geográficas, responsabilidades del Estado, organización administrativa del ministerio rector, financiamiento, formas de protección de la vida silvestre, regulaciones de caza, investigación científica, derecho a pesca, importación y exportación de especies, refugios de vida silvestre, sanciones y contravenciones. Como puede notarse, el tema de la participación es prácticamente omiso, a no ser por el planteamiento establecido en el artículo 15 :

"Para coadyuvar a la aplicación y cumplimiento de esta ley, el Ministerio de Ambiente y Energía nombrará inspectores de vida silvestre; inspectores ad honorem de vida silvestre y comités de vigilancia de los recursos naturales" (COVIRENAS)

La participación que se sugería tiene un carácter eminentemente de inspección y vigilancia de los recursos (tipo policial), no así de participación en la toma de decisiones y en el manejo y promoción de los derechos ambientales de la sociedad costarricense. Vale la pena recordar que esta administración gubernamental se caracterizó entre otras cosas por su incongruencia hacia los temas ambientales, y durante el último año de su gestión, tuvo un marcado pulso con organizaciones ambientalistas del sur del país, dada su insistencia por apoyar un proyecto que pretendía industrializar madera en la Península de Osa, quizás la zona con mayor biodiversidad y riqueza escénica del país.

Sin embargo, la presión social por aumentar su influencia en la conservación del medio ambiente fue sostenida, y encontró un escenario favorable en la gestión Figueres Olsen (1994-1998), la cual impulsó y aprobó importante legislación orientada a generar condiciones de sostenibilidad ambiental, dentro de ésta, la participación social tuvo un lugar "privilegiado". Estas acciones en buena medida se explican por los compromisos que había asumido el gobierno anterior en la Conferencia de Río de Janeiro del año 95, a la sensibilidad que el gobierno mostraba hacia el tema, y a la presión que diferentes ONGs y grupos locales ejercían sobre el gobierno con el propósito de articularse en iniciativas de protección del medio ambiente que fueran más allá de los planteamientos del gobierno.

Similar a su antecesora, esta administración mostró marcadas contradicciones entre su discurso ambiental y las prácticas realizadas. Si bien resolvió de forma favorable a los intereses de los sectores conservacionistas la disputa que había con la compañía canadien- 
$\mathrm{se}^{12}$, el medio ambiente siempre fue entendido como una fuente de recursos ${ }^{13}$ que debía ser explotada en función de los intereses capitalistas, comprometiendo así los anhelados esfuerzos de sostenibilidad ambiental.

La concepción de participación que se plasma en esta legislación es sumamente limitada y tiende a poner techos a la participación, una especie de consigna que dice: "usted, su comunidad, amigos o grupos locales pueden participar, pero sin pasarse de este límite, nosotros decimos en qué y hasta dónde pueden participar"; participar no puede enfrentar o contradecir los intereses económicos dominantes, particularmente cuando estos se articulan a la dinámica de producción capitalista imperante en el país. Sin embargo, la mencionada legislación legitimó numerosas posibilidades para que las comunidades y diferentes grupos locales se fueran involucrando de forma activa en iniciativas de conservación de los recursos naturales.

La estructura de los COVIRENAS se utilizó inicialmente como una acción del aparato estatal para burocratizar la participación social y ponerla en función de los intereses dominantes (sin dejar de incluir en la agenda pública la conservación ambiental), procurando evitar y enfrentar otras formas de organización social que eran contestatarias a las propuestas del gobierno. A lo largo y ancho del país esta figura se fue expandiendo, particularmente en los lugares con mayor riqueza ecológica.

\section{La singularidad de la ASOCOVIRENAS}

En poco más de una década -y en el caso particular de la zona sur- los COVIRENAS evolucionaron hasta convertirse en ASOCOVIRENAS (Asociación de Comités de Vigilancia de los Recursos Na-

12 Anteriormente hicimos mención al conflicto que se generó entre la compañía Ston Forestal, grupos conservacionistas y las comunidades aledañas al proyecto, mismo que fue heredado a la administración Figueres, la solución que se brindó por parte de este gobierno marcó una ruptura importante con la forma como los diferentes gobiernos habían manejado el tema medio ambiental y en el mediano y largo plazo, ello generaría importantes acciones entre los pobladores de la zona y grupos vinculados con el tema de la sostenibilidad ambiental.

13 Y no sólo en el campo de la explotación de los recursos, sino en la figura de una serie de convenios de cooperación con organizaciones internacionales que facilitaban recursos económicos y tecnológicos para fortalecer la sostenibilidad ambiental. 
turales), los cuales además de incorporar las tareas de vigilancia, desarrollan acciones de promoción social, capacitación y educación ambiental, negociación, creación de redes y captación de recursos entre otras acciones. En suma, una práctica política de inclusión de intereses, defensa, promoción, negociación, organización y construcción de un proyecto de desarrollo regional que logre armonizar la sostenibilidad ambiental con las necesidades humanas y la identidad cultural regional.

Cabe destacar que la figura de los ASOCOVIRENAS no se contempla en la legislación costarricense, sino que se corresponde a un esfuerzo político de varios actores sociales de la zona sur por aprovechar los espacios que brinda el Estado y ampliarlos tanto en materia de objetivos, participación y militancia política, sostenibilidad ambiental y búsqueda de un modelo de desarrollo que logre armonizar las necesidades del ser humano y la sostenibilidad ambiental. Algunas de las cualidades más sobresalientes de las ASOCOVIRENAS se resumen en:

\section{Re politización}

Una de las dimensiones con un carácter eminentemente estratégico tiene que ver con la capacidad que han desarrollado las ASOCOVIRENAS para aprovechar y ampliar la figura de los COVIRENAS en función de los intereses vinculados con el desarrollo sostenible. Esta situación les brinda legitimidad ante el Estado a la vez que aprovecha las oportunidades de coordinación, denuncia y respaldo legal que la legislación les ofrece. Existe un reconocimiento de que los COVIRENAS nacen con limitaciones estructurales, pero que brindan oportunidades para facilitar la participación, articular nuevas experiencias y organizaciones aprovechando los espacios que facilita el Estado. Es una estrategia política para "tomar" los espacios que el Estado brinda, re-politizando desde la base la participación que se había concebido de forma institucionalizada e integrando tanto preocupaciones y compromisos y sociales y ambientales.

\section{Inclusión y ampliación}

Se denota un esfuerzo por incorporar nuevos actores sociales (mujeres, jóvenes, grupos productivos, indígenas), y ampliar las temáticas ambientales más allá de la protección de bosques, especies o cuencas (manejo de desechos sólidos, ornato, formación de sensi- 
bilidad ambiental, educación ambiental en escuelas). Este esfuerzo garantiza sostenibilidad organizacional en la medida que los líderes fundadores tienen la disposición para incorporar nuevos actores y trasmitirles sus conocimientos y experiencias políticas; por otro lado, las personas participantes están en capacidad de organizarse para defender sus derechos sociales y ambientales. Esto lleva a un reconocimiento de que los sectores populares organizados están en capacidad de tomar decisiones y ser propositivos.

\section{Unidad en la diversidad}

Entre los que hemos denominado líderes "históricos" existe una tradición de participación asociada con la izquierda ${ }^{14}$, esta situación no ha sido una limitante para incorporar en este esfuerzo de sostenibilidad ambiental a personas y grupos que no pertenecen a la izquierda. La idea fundamental parece ser articular a todas aquellas personas y sectores que muestren sensibilidad e iniciativa organizativa por la protección de los recursos naturales y que estén dispuestas a participar en procesos de toma de decisiones y protección del medio ambiente; esta condición incluso les facilita la posibilidad de articularse con ONGs o con el Ministerio del Ambiente y Energía (MINAE). Las ASOCOVIRENAS parten del principio de que es más conveniente integrar esfuerzos entre las diferentes organizaciones de la zona, antes que convertir el trabajo en una lucha infructífera de protagonismos que terminen por menoscabar los objetivos de conservación y aprovechamiento sostenible de los recursos.

Sin lugar a dudas, esta disposición muestra un mayor nivel de madurez política, particularmente cuando en algunos sectores de la izquierda existe la tradición de condenar el trabajo con sectores que no les son afines ideológicamente ${ }^{15}$, y responde a una lectura reno-

14 Recuérdese que en esta zona durante los años '80 existía una gran influencia del Partido Vanguardia Popular, el que realizaba un intenso trabajo con los sindicatos que protegían los derechos de los empleados de la compañía bananera que estaba instalada en la zona.

15 El desarrollo de la izquierda costarricense es muy particular y denota en algunos sectores la capacidad para distanciarse de ciertos dogmas seudo marxistas y leninistas que niegan esta posibilidad de establecer alianzas y concebir la realidad política. Ya en los años 40 del siglo XX, la alianza política entre el Partido Comunista, la Iglesia Católica y el Partido Republicano permitieron la aprobación de las Garantías Sociales, fundamentales para el posterior desarrollo de la seguridad social costarricense y del Estado que conocemos en la actualidad. 
vada de la situación nacional en la cual resulta estratégico negociar con diferentes actores sociales sin comprometer los principios políticos por los cuales se lucha.

\section{Vigilancia, formación y acción política}

Cualquier persona que esté interesada puede formar parte de los COVIRENAS, luego de recibir la respectiva acreditación, se dedica básicamente a tareas de vigilancia y denuncia. Con su incorporación a los ASOCOVIRENAS estas acciones se amplían sustantivamente pues las personas, grupos y comunidades de la zona no solo son sujetos de capacitación y formación, sino que se involucran en una serie de actividades de negociación, encuentro, discusión, creación y/o fortalecimiento de redes, participación, y ejecución de acciones. Paulatinamente, los integrantes de los ASOCOVIRENAS se ven a sí mismos más como actores sociales, como ciudadanos, en palabras de Hopenhayn (1988), las personas son menos objeto y más sujeto. Ser parte de ASOCOVIRENAS implica involucrarse en un proceso de formación y práctica política articulado en este caso con la sostenibilidad ambiental.

\section{Gestión administrativa}

El trabajo que desarrolla la ASOCOVIRENAS se caracteriza por apoyarse en un proceso administrativo en el que es factible programar actividades de planificación, ejecución, control y evaluación. Ante la complejidad del entorno y las presiones constantes que se reciben por expandir la actividad económica depredadora en la zona, fue igualmente necesario apoyarse en una gestión administrativa que garantizara el cumplimiento de los objetivos que la organización se trazó. Se identificó que incluso la organización ha desarrollado la capacidad para contar con financiamiento de la cooperación internacional. La coordinación que mantienen con comunidades, ONGs e instituciones públicas, además de dar cuenta de la legitimidad que tiene la ASOCOVIRENAS, hace referencia a una dimensión administrativa que facilita este proceso de trabajo.

\section{Hacia redes nacionales}

La experiencia de la ASOCOVIRENAS es muy particular en la medida que ha ampliado el rango de competencias inicialmente estableci- 
do por la legislación. Esta situación les ha facilitado condiciones para articularse con otras organizaciones afines como COVODES en la Zona de San Carlos y otras agrupaciones en la zona del Caribe costarricense, trabajando de forma conjunta temas como formación, intercambio de información y apoyo político cuando lo requieren. Este esfuerzo colectivo supone la posibilidad de una articulación nacional que profundice las acciones de movilización, coordinación, intercambio de información y experiencias, capacidades de presión y negociación, balance de coyuntura nacional, y profundización del movimiento conservacionista, especialmente en espacios locales donde se materializan otras formas de articularse con la problemática ambiental y es urgente posicionarse como ciudadanos y actores sociales empoderados.

\section{Debate y sostenibilidad ambiental}

Un esfuerzo de esta magnitud no se puede dar en el vacío, se sustenta en principios y acciones políticas, en una tradición de participación que paulatinamente se va ampliado. En el seno de estar organización, particularmente con los líderes que tienen una tradición de izquierda, existe un rico debate sobre las opciones de desarrollo, las formas de participación y organización en la zona y la interpretación de las condiciones políticas que los afectan. Este debate tiende a incluir otras posiciones y actores sociales, partiendo del hecho de que un modelo de desarrollo sostenible se construye de forma participativa. Esta discusión nutre a los diferentes grupos de la zona, particularmente quienes forman parte de la ASOCOVIRENAS.

\section{¿Por qué la re politización?}

Una pregunta fundamental surge a esta altura de la discusión: ¿Qué hace diferente a los COVIRENAS DE LOS ASOCOVIRENAS?, o si se quiere, ¿por qué los ASOCOVIRENAS han optado por re-politizar las limitadas acciones de los COVIRENAS?

Una primera parte de la respuesta podemos encontrarla en las relaciones sociales y políticas establecidas a partir de la principal actividad productiva que caracterizó a la zona sur hasta la década de los '80: la bananera. A mediados de la década de 1930 la United Fruit Company (UFCO) trasladó las actividades que tenía en la zona atlántica del país al pacífico sur costarricense, y con ella también 
se trasladó la combativa experiencia sindical que se había desarrollado con los trabajadores de las plantaciones bananeras el caribe. Con una clara influencia del Partido Comunista costarricense, se desarrollaron extensas y complejas luchas y huelgas que pusieron en jaque a la compañía y a los gobiernos de aquellos años, y abrieron importantes espacios de defensa de los derechos de la población trabajadora.

Para el caso de la zona sur, el Partido Vanguardia Popular -igualmente de izquierda- desarrolló un amplio proceso de formación de cuadros que incluyó a centenares de líderes y trabajadores de la United Fruit Company (UFCO) ${ }^{16}$, así como mujeres y adolescentes; este proceso de formación política sentó condiciones de organización y participación social que se extenderían con el tiempo en diferentes actores locales, facilitando así avanzar en un proceso sinérgico de exigibilidad de derechos ${ }^{17}$ que dichosamente tuvo la capacidad de articularse con las situaciones que amenazan la sostenibilidad ambiental.

Otro aspecto que influye en la re politización de los COVIRENAS está asociado con la lucha que desarrollaron ONGs, grupos ambientalistas y vecinos de la zona para evitar la ampliación de actividades de la compañía Ston Forestal. Como se expresó anteriormente, la pretensión de esta compañía era procesar la madera en astillas de madera e instalar un puerto de embarque en la zona más interna del Golfo Dulce, situación que a criterio de diversos investigadores y actores sociales, tendría un impacto devastador en la ecología del lugar.

Entre la gran diversidad de actores locales que se articularon a esta lucha, muchos/as de ellos/as tenían una experiencia de militancia con el Partido Vanguardia Popular, situación que influyó de forma

16 En los años 80 del siglo XX la UFCO tomó la decisión de trasladar una buena parte de sus actividades productivas a Honduras, sumiendo a la zona sur en una situación económica caótica pues una buena parte del empleo estaba asociado con la producción de banano.

17 El concepto sinergia refiere a una capacidad de auto reproducción que no se agota, se extiende de forma infinita. Su significado en las Ciencias Sociales es similar y sugiere que un proceso social desencadena nuevos procesos que avanzan en la misma dirección. En el pasado los esfuerzos de formación desarrollados en la zona promocionaron los derechos laborales de los trabajadores bananeros; desaparecida esta actividad económica, los esfuerzos locales se reorientaron entre otras acciones a la promoción de los derechos ambientales. 
determinante en las formas de organización, la capacidad de resistencia, de negociación y articulación con otros actores sociales. También los integrantes de la Asociación Ecológica Costarricense (AECO) -ONG que tuvo un protagonismo indiscutible- tenían una tradición de izquierda que influyó de forma determinante en el desarrollo de esta lucha social.

La presión local, nacional e internacional obligaron a la Administración Figueres Olsen a asumir una solución que resultó favorable a muchas de las demandas que los sectores conservacionistas habían planteado, particularmente evitar la construcción de la planta astilladora y el muelle de embarque en Punta Estrella. Esta decisión impactó de forma positiva en las diferentes organizaciones conservacionistas y actores locales involucrados, particularmente en su capacidad de empoderarse e imaginar nuevas estrategias de acción y organización que estuvieran en consonancia con la sostenibilidad ambiental y la construcción de un modelo de desarrollo inclusivo y participativo.

La lucha contra la Ston Forestal -o campaña del sur como también se le denomina- influyó en la necesidad de desarrollar experiencias políticas de protección de los recursos naturales. Varios de estos actores se integran hoy en día en la estructura de la ASOCOVIRENAS.

Un tercer componente de la respuesta tiene que ver con las cualidades e iniciativas de sus líderes fundadores y con las capacidades que ha desarrollado la ASOCOVIRENAS a lo largo del tiempo; estas dos dimensiones están imbricadas.

La formación histórica y política de sus líderes les ha facilitado reconocer que lo ambiental es también un derecho a proteger y por lo tanto objeto de sus acciones políticas. En palabras de una de las entrevistadas:

"... hay una historia y liderazgo que se traduce a la parte ambiental y que los convierte en una vanguardia. Han tenido una experiencia muy política, una historia de vida interesante y política que logra generar prácticas transformadoras..."

A la afirmación de la entrevistada solo puede agregársele la reflexión de que "experiencias políticas de esa naturaleza, necesariamente tienen que desembocar en nuevas prácticas políticas que fortalezcan los movimientos populares y la ampliación de los derechos socia- 
les". La expansión de los COVIRENAS en ASOCOVIENAS responde a un proceso histórico de formación y empoderamiento; un esfuerzo por aprovechar, conquistar y posicionarse en los espacios que brinda el Estado para favorecer la sostenibilidad ambiental y garantizar que los intereses de los sectores sociales sean incluidos en la agenda pública. Esta iniciativa supone que las comunidades tienen la capacidad y obligación de tutelar y promocionar sus derechos, sin descartar la intervención del Estado como garante de los mismos.

\section{Tareas pendientes}

Entre las principales tareas que se plantea la ASOCOVIRENAS para realizar en el mediano y corto plazo sobresalen:

- Mantener los esfuerzos de vigilancia y denuncia, sea que se cuente o no con el apoyo del Ministerio de Ambiente y Energía.

- Fortalecer la capacitación, formación, creación de redes, análisis de la realidad y desarrollo de un trabajo político con sus integrantes.

- Generar espacios de intercambio, coordinación y trabajo conjunto con otros actores locales de la zona, así como con instancias gubernamentales y otras organizaciones ambientales nacionales y regionales.

- Incorporar más COVIRENAS dentro de la experiencia de la ASOCOVIRENAS, se reconoce que una buena parte de estos comités aún no forma parte de su experiencia. Indiferentemente de que aún varios comités no participen se les da el mismo tratamiento de los que ya participan pues el tema medular para ellos es generar sostenibilidad y conciencia y experiencia política ${ }^{18}$.

- El trabajo de la ASOCOVIRENAS fue dirigido especialmente hacia la zona de la península y la Gamba (Golfito), descuidando el trabajo en las zonas más urbanas o con mayores concentraciones de población en los que existe un significativo potencial de participación y acción. Es por esta razón que se está realizando un esfuerzo de articulación con las Asociaciones Administradoras de Acueductos Comunales (ASADAS) y con diversos comités en Alto Conte (Punta Burica) y Alto Guaní, con la pretensión de

18 Muchos COVIRENAS que aún no forma parte de ASOCOVIRENAS son campesinos que viven en las zonas de amortiguamiento del Parque Nacional Corcovado, tienen una gran motivación para trabajar y eso hay que rescatarlo e impulsarlo por medio del apoyo de su organización. 
disminuir la casa, la tala y mejorar el manejo de los recursos hídricos.

- Con los jóvenes -particularmente de las zonas urbanas- se intenta realizar diferentes tipos de trabajo, entre ellos sensibilizarlos ante la problemática ambiental e integrarlos en acciones de protección y mantenimiento del Parque Nacional Corcovado, Piedras Blancas y la misma Reserva Golfo Dulce. Esta iniciativa contempla la realización de intercambios entre jóvenes de diferentes lugares de la zona con jóvenes provenientes de lugares donde se hayan desarrollado experiencias exitosas de sostenibilidad ambiental.

- Con la población escolar es necesario fortalecer la educación ambiental, particularmente por su efecto multiplicador en el mediano y largo plazo, para el año 2006 se contaba con más de 500 niños y niñas participando en diferentes programas específicos en diversas escuelas de la zona.

- Fortalecer el trabajo interno con el propósito de superar el trabajo que realizan en la actualidad y consolidarse ellos mismos y otras agrupaciones, lo que les permitirá profundizar logros en materia de vigilancia, denuncia, conservación, manejo de recursos naturales, participación, capacitación y creación de tejido social.

\section{Hacia un balance}

En la actualidad pueden identificarse al menos tres debates sobre el rol del Estado en el marco de la sociedad capitalista. El dominante sugiere que el Estado debe avocarse a garantizar las condiciones mínimas para que el capital pueda desarrollarse por su cuenta con la menor injerencia de éste. Todas las relaciones sociales se mercantilizan y lo que en el pasado era un derecho, en la actualidad se convierte en un bien de consumo. La política social es espuria, en el mejor de los casos se focaliza y se desarrolla desde una concepción asistencialista (Molina y Romero 2001). Sus antecedentes los tenemos en el neoliberalismo y particularmente con el Consenso de Washington que pretendían desmantelar la seguridad social pública y al mismo Estado.

Un segundo debate y que ha tomado un auge inusitado -particularmente luego de la debacle neoliberal en la región y de la llegada al poder de gobiernos de izquierda en Venezuela, Bolivia y Ecuador- ve 
en el Estado la fuerza para distribuir riqueza y generar procesos de desarrollo económico y social inclusivos. No es el regreso al Estado de Bienestar, sino un Estado que es concebido con nuevas atribuciones, motor de desarrollo, inclusión ciudadana y ruptura con el orden capitalista. Lo social nuevamente se asume como un derecho y la política social cobra nuevamente vigencia como forma de distribución de riqueza y potenciación de los derechos humanos.

Aunque con modificaciones y mutilaciones, el Estado de Bienestar keynesiano aún mantiene vigencia en algunos países de la región (Costa Rica y Uruguay), y algunos procesos políticos de países como Argentina, Brasil o el mismo Chile hacen presumir que la racionalidad económica y social de este modelo sigue funcionando y potenciando la producción económica. Igual que en el caso anterior, hay una exigencia por reconocer lo social como un derecho de la ciudadanía, pero sus limitaciones organizacionales e instrumentales son mayores.

En materia de participación social, desde el alzamiento zapatista en México hay un reposicionamiento y resignificación de ésta. El Estado de Bienestar con su centralización limitó en buena medida la participación social, el Estado mínimo procuró evitarla o reorientarla a sus intereses mercantiles, y el nuevo Estado socialista -en aparente transición y construcción- apuesta por ella para garantizar su reproducción como Estado.

Al margen de estas manifestaciones materiales del Estado, toca reflexionar sobre las experiencias de participación que se han desarrollado en los últimos 25 años en la región y la forma como han influido en el mantenimiento y construcción de la política social. En muchos países la participación fue desmontada aunque siempre existieron focos de presión y organización social que no lograron evitar la privatización del bienestar (Mann, 1992); en otros, como en el caso nacional, la presión social y el apoyo al Estado de Bienestar, lograron la conservación de ésta pero con limitaciones de inversión, cobertura y calidad.

Palma (2002) sugiere la existencia de un nuevo proceso de participación e inclusión ciudadana que denomina "asociatividad popular", en el cual si bien la persona se distancia con las estructuras tradicionales de participación mantiene su inquietud por defender sus derechos sociales y económicos, y esboza la siguiente hipótesis: 
"Durante las últimas tres décadas, los cambios profundos que se han producido en sectores diversos se han traducido en transformaciones en las pautas de sociabilidad, de donde resulta que surgen más y nuevas dificultades para quienes buscan repetir las formas de asociación que eran dominantes (y que resultaban) hace pocas décadas; en cambio resulta más fácil organizar cuando se invita a incorporarse en formas de organización nuevas y distintas".(Palma 2002)

Es así como podríamos decir que las ASOCOVIRENAS y otras formas de organización social articuladas a la conservación ambiental, parecieran entrar en esta expresión de participación, particularmente por el esfuerzo de generar espacios de acción local en la cual las mismas organizaciones y comunidades desarrollan de forma exitosa y concertada procesos de diseño y ejecución de políticas, educación, organización, negociación, búsqueda de recursos, creación de redes y construcción de polos de poder que favorecen la tutela, promoción y disfrute de sus derechos humanos, incluyendo el derecho a un medio ambiente sostenible.

Avanzar en un proceso de esta naturaleza, favorece la apropiación de iniciativas políticas en el marco de las políticas públicas y sociales por parte de los sectores populares, esto es, siguiendo a Pastorini (2000) reconocer que estas acciones tienen una dimensión de conquista que se deriva de las relaciones conflictivas que se dan entre diferentes actores sociales.

\section{Bibliografía}

Camacho, Daniel (1987).

"Movimientos sociales, algunas discusiones conceptuales". En: Revista de Ciencias Sociales, \# 37-38. Setiembre-diciembre. Universidad de Costa Rica. San José. Costa Rica.

Fallas, Oscar (1992). Modelos de Desarrollo. I Serie Cuadernos de Estudio. Asociación Ecológica Costarricense. Costa Rica.

Hopenhayn, Martín (1998).

"La participación y sus motivos". I Parte. En: Revista Acción Crítica. \# 24. Perú.

Mann, Kirk (1992). "Privatización del Bienestar, individualismo y Estado". En: Cuadernos de Ciencias Sociales, \# 48. 
Facultad Latinoamericana de Ciencias Sociales. Costa Rica.

Molina, Lorena; Romero, María (2001).

Modelos de intervención asistencial, socioeducativo y terapéutico en Trabajo Social. Editorial de la Universidad de Costa Rica. Costa Rica.

Pastorini, Alejandra (2002).

“¿Quién mueve los hilos de las políticas sociales? Avances y límites en la categoría 'concesión-conquista'”. En: Borgiani, Elisabete; Montaño, Carlos (Compiladores) La política social hoy. Cortez. Brasil.

Salazar, Mora; Calderón, Guardia (1985).

Una biografía política. EUNED. Costa Rica.

\section{Recursos electrónicos:}

Palma, Diego (2002). "La asociatividad popular". En: 2do. Encuentro Latinoamericano Zona Sur. Experiencias de intervención en constitución de sujeto y ciudadanía. Chile. www.ts.ucr.ac.cr 